\title{
Paratuberculose em caprinos e ovinos no Estado da Paraíba ${ }^{1}$
}

\author{
João M.A. Medeiros ${ }^{2}$, Felício Garino Junior ${ }^{2}$, Arthur P. Almeida ${ }^{2}$, Erasmo A. Lucena ${ }^{2}$ \\ e Franklin Riet-Correa ${ }^{2 *}$
}

\begin{abstract}
Medeiros J.M.A., Garino Jr F., Almeida A.P., Lucena E.A. \& Riet-Correa F. 2012. [Paratuberculosis in goats and sheep in the state of Paraiba.] Paratuberculose em caprinos e ovinos no Estado da Paraíba. Pesquisa Veterinária Brasileira 32(2):111-115. Hospital Veterinário, Centro de Saúde e Tecnologia Rural, Campus de Patos, Universidade Federal de Campina Grande, Patos, PB 58700-000, Brasil. E-mail: franklin.riet@pq.cnpq

Antibodies to paratuberculosis were determined by ELISA in serum samples of 734 goats and 392 sheep, without clinical signs, from 14 municipalities of the semiarid region of Paraíba state, Brazil. In goats, average frequency of antibodies was $44.86 \pm 22.91 \%$ and in sheep was $52.96 \pm 31.49 \%$. All municipalities had affected animals with a frequency varying from $20 \%$ to $70 \%$. In goats of unknown breed and crossbreds the prevalence (48.56\%) was significantly lower $(\mathrm{P}=0.0270)$ than in pure breed goats $(57.24 \%)$. In sheep with body scores of 1 to 3 , the frequency $(59.39 \%)$ was significantly higher $(\mathrm{P}=0.0034)$ than in sheep with body score from 3 to $5(42.42 \%)$. No significant differences were observed in goats and sheep of different ages, in goats with different body score, and in sheep of different breeds. In the microbiologic examination, after 16 weeks of incubation in HEYM medium with mycobactin J, colonies similar to those of do Mycobacterium avium subsp. paratuberculosis were observed in cultures of $9(6.58 \%)$ out of 180 fecal samples, being one from goats and 8 from sheep. In the Ziehl Nieelsen the bacteria had morphologic and staining characteristics similar to M. avium subsp. paratuberculosis. These results suggest that paratuberculosis is endemic with high prevalence in the semiarid region of Paraíba. It is necessary to develop research on the epidemiology and control measures of the disease in the conditions of this region. Also the risk for human beings should be determined, mainly in relation with milking goats.
\end{abstract}

INDEX TERMS: ELISA, Mycobacterium avium subsp. paratuberculosis, paratuberculosis, small ruminants.

RESUMO.- Mediante o teste de ELISA foi determinada a presença de anticorpos para Mycobacterium avium subsp. paratuberculosis (map) em amostras de soro de 734 caprinos e 392 ovinos, sem sinais clìnicos aparentes, provenientes de 14 Municipios do semiárido Paraibano. Em caprinos, a frequência média de anticorpos de $44,86 \pm 22,91 \%$ e em ovinos foi de $52,96 \pm 31,49$. Das 46 propriedades estudadas, $44(95,65 \%)$ apresentaram pelo menos um animal soropositivo. Nos 14 municípios avaliados houve presença de animais sorologicamente positivos, variando de $20 \%$ a $70 \%$. Em caprinos sem raça definida e mestiços a frequência

\footnotetext{
${ }^{1}$ Recebido em 27 de junho de 2011.

Aceito para publicação em 10 de outubro de 2011.

${ }^{2}$ Hospital Veterinário, Centro de Saúde e Tecnologia Rural (CSTR), Campus de Patos, Universidade Federal de Campina Grande, Patos, PB 58700000, Brasil.*Autor para correspondência: franklin.riet@pq.cnpq
}

$(48,56 \%)$ foi significativamente inferior $(\mathrm{P}<0,0270)$ que a de caprinos de raças puras $(57,24 \%)$. Em ovinos com escore de 1 a 3 a frequência $(59,39 \%)$ foi significativamente maior $(\mathrm{P}=0,0034)$ que a frequência em ovinos com escore superior a $3(42,42 \%)$. Não houve diferença significativa nas frequências em caprinos e ovinos de diferentes idades, em caprinos com diferente escore corporal e em ovinos de diferentes raças. No exame microbiológico, em cultivos em meio HEYM com micobactina J, foram observadas colônias semelhantes às do Map em 9 (6,58\%) das 180 amostras de fezes, sendo uma de caprinos e 8 de ovinos. Na coloração de Ziehl Nieelsen as bactérias apresentavam características morfo-tintorias de Map. Os resultados obtidos indicam alta frequência de caprinos e ovinos infectados com Map no semiárido da Paraíba, tornando-se necessário desenvolver pesquisas sobre a epidemiologia e forma de controle da doença nas condições de criação da região. 
TERMOS DE INDEXAÇ̃̃O: ELISA, Mycobacterium avium subsp. paratuberculosis, paratuberculose, pequenos ruminantes.

\section{INTRODUÇÃO}

A paratuberculose ou doença de Johne é uma enfermidade infecto-contagiosa crônica, incurável, de distribuição mundial. Acomete bovinos, ovinos, caprinos, bubalinos e outros ruminantes selvagens e, com menor frequência, suínos, lebres e equinos. 0 agente etiológico é o Mycobacterium avium, subespécie paratuberculosis (Map), que causa enterite e linfadenite granulomatosas (Clarke 1997, Harris \& Barletta 2001, Barker 2007, Riet-Correa \& Driemeier 2007, Moravkova et al. 2008).

A doença é responsável por perdas econômicas importantes em vários países, principalmente nos EUA, onde foi verificado um prejuízo de 200 a 250 milhões de dólares por ano (Ott et al. 1999).

A infecção em ruminantes ocorre após o nascimento, principalmente pela ingestão de água e alimentos contaminados ou com fezes, leite e colostro de animais infectados (Clarke 1996). Ocorre também transmissão pela via intra-uterina (Radostits et al. 2007).

Em ovinos e caprinos, a doença manifesta-se, principalmente, por emaciação progressiva; a diarréia não é grave ou está ausente, diferente dos bovinos em que a diarreia é um sinal clínico característico. Os ovinos podem ser parcialmente anoréxicos e pode ocorrer perda de lã. Nos caprinos, a depressão e a dispnéia são evidentes, mas nos ovinos não são tão visíveis (Radostits et al. 2007). 0 diagnóstico dos casos subclínicos pode ser realizado por isolamento de bactérias das fezes ou leite e provas sorológicas. 0 diagnóstico confirmatório pode ser por material de necropsia e por estudo histológico das lesões (Riet-Correa \& Driemeier 2007).

Diversos testes sorológicos têm sido utilizados para verificar a presença de anticorpos contra o Map nos rebanhos (Tripathi et al. 2006). ELISA é visto como teste sorológico de eleição, principalmente pela conveniência da coleção de amostras, procedimento laboratorial rápido e de baixo custo. A especificidade deste teste se torna elevada pela absorção do soro com outra micobactina, do Mycobacterium phlei, o que remove os anticorpos não específicos, evitando assim as reações cruzadas contra os antígenos do Map. Os testes comerciais que incorporam antígenos mais específicos ao Map proporcionam uma sensibilidade de detecção de $70 \%$ a $80 \%$ e uma especificidade de $89 \%$ a 95\% (Stabel 1998).

No Brasil há relatos da paratuberculose em bovinos em diversos Estados das regiões Sul e Sudeste (Portugal et al. 1979, Ramos et al.1986, Poester \& Ramos 1994, Driemeier et al. 1999, Gomes et al. 2002) e também nos Estados de Pernambuco (Mota et al. 2007) e Paraíba (Oliveira et al. 2008). Em ovinos e caprinos a doença foi recentemente diagnosticada na Paraíba (Oliveira et al. 2010).

Devido às características da paratuberculose em caprinos e ovinos, causando emagrecimento ou menor produtividade, a doença pode ser confundida com outras causas de emagrecimento; portanto é provável que, na região semiárida do Brasil, seja subdiagnosticada, ocasionando perdas econômicas significativas. O objetivo deste trabalho foi estimar a frequência de anticorpos contra o Map em caprinos e ovinos no semiárido Paraibano.

\section{MATERIAL E METODOS}

O projeto foi realizado no período de novembro de 2009 a dezembro de 2010. As amostras foram coletadas em rebanhos de quatro mesorregiões da Paraíba (Sertão, Cariri Ocidental, Cariri Oriental e Agreste) que tem o maior número de caprinos e ovinos do Estado. Foram testadas 734 amostras de soro de caprinos e 392 de ovinos, assintomáticos, de 46 rebanhos diferentes. Os rebanhos foram escolhidos de acordo com a possibilidade de acesso às fazendas e a concordância dos produtores. Em cada fazenda foram coletadas amostras de aproximadamente $10 \%$ dos animais. De cada animal foram coletados $10 \mathrm{~mL}$ de sangue por venopunção da jugular com agulhas acopladas a tubos a vácuo. Foram coletadas, também, amostras de fezes, colhidas da ampola retal de 86 caprinos e 94 ovinos positivos na prova de ELISA. A seleção dos animais para a coleta das amostras também foi por conveniência. 0 acesso aos produtores foi através dos agentes de desenvolvimento rural sustentável do projeto Bioma Caatinga da Paraíba.

As amostras de sangue foram centrifugadas a $1700 \mathrm{xg}$ por 15 minutos e os soros transferidos para 3 tubos de Eppendorf de $3 \mathrm{~mL}$ cada, mantidos a $-70^{\circ} \mathrm{C}$ e, posteriormente testadas pelo teste de ELISA utilizando um kit comercial $^{3}$ anti-Map. Para a leitura do teste de ELISA utilizou-se uma Leitora de microplaca ${ }^{4}$. Para a interpretação dos resultados dos animais positivos no teste de ELISA foi considerado um ponto de corte de $\mathrm{P}>0,250$, conforme indicação do fabricante.

Para o exame microbiológico foram utilizadas amostras de fezes dos animais de cada propriedade que tiveram maior título no teste de ELISA. As amostras de fezes foram cultivadas de acordo com a metodologia descrita por Stabel (1997). As análises estatísticas foram realizadas por meio do teste de Qui-quadrado $\left(\mathrm{x}^{2}\right)$ com correção de Yates e o nível de significância adotado foi de $5 \%$. Os dados foram analisados estatisticamente utilizando o programa GRAPHPAD INSTAT versão 3.00 para Windows 95, GraphPad Software.

\section{RESULTADOS}

Os resultados dos testes sorológicos por fazenda, em caprinos e ovinos, apresentam-se nos Quadros 1 e 2 , respectivamente. Das 46 propriedades estudadas, $44(95,65 \%)$ apresentaram pelo menos um animal soropositivo. Em caprinos, a frequência média foi de $44,86 \pm 22,91 \%$, em ovinos foi de $52,96 \pm 31,49 \%$. Somente em uma propriedade de ovinos e uma de caprinos não foram encontrados animais positivos.

As frequências por município, raça, idade e escore corporal encontram-se nos Quadros 3, 4, 5, 6 e 7, respectivamente.

Nos 14 municípios estudados observou-se a presença de animais sorologicamente positivos, variando de $20 \%$, em Maturéia, Soledade e Paulista, localizadas no sertão, a $70 \%$ em Campina Grande, localizado no agreste e São Mamede, no sertão.

Não foram encontradas diferenças significativas entre as raças (Quadro 4); no entanto, quando foram comparados os dados dos animais sem raça definida e mestiços,

\footnotetext{
${ }^{3}$ Alamar Tecno-Científica Ltda, Diadema, SP, Brasil.

${ }^{4}$ Pharma Nostra, São Paulo, Brasil.
} 
Quadro 1. Resultados dos testes de ELISA, para detecção de anticorpos contra o Map em 734 amostras de caprinos em 32 propriedades de 10 municípios do semiárido Paraibano

\begin{tabular}{|c|c|c|c|c|}
\hline Fazenda/município & Total & Testados & Positivos & $\%$ \\
\hline 1/Patos & 64 & 30 & 13 & 43,33 \\
\hline 2/Patos & 12 & 8 & 6 & 75,00 \\
\hline 3/Ouro velho & 55 & 30 & 16 & 53,33 \\
\hline 4/Ouro velho & 45 & 18 & 10 & 55,56 \\
\hline 5/Ouro velho & 27 & 17 & 16 & 94,12 \\
\hline 6/Ouro velho & 65 & 21 & 6 & 28,57 \\
\hline 7/Ouro velho & 300 & 22 & 12 & 54,55 \\
\hline 8/Prata & 150 & 43 & 28 & 65,12 \\
\hline 9/Prata & 140 & 21 & 8 & 38,10 \\
\hline 10/Prata & 59 & 16 & 2 & 12,50 \\
\hline 11/Prata & 76 & 26 & 15 & 57,69 \\
\hline 12/Prata & 50 & 31 & 16 & 51,61 \\
\hline 13/ Amparo & 100 & 44 & 28 & 63,64 \\
\hline 14/ Amparo & 56 & 21 & 9 & 42,86 \\
\hline 15/ Amparo & 34 & 16 & 10 & 62,50 \\
\hline 16/ Amparo & 63 & 28 & 7 & 25,00 \\
\hline 17/ Amparo & 100 & 15 & 7 & 46,67 \\
\hline 18/Sumé & 78 & 22 & 7 & 31,82 \\
\hline 19/Sumé & 65 & 18 & 4 & 22,22 \\
\hline 20/Sumé & 50 & 27 & 15 & 55,56 \\
\hline 21/Sumé & 70 & 21 & 9 & 42,86 \\
\hline 22/Sumé & 120 & 20 & 6 & 30,00 \\
\hline 23/ Monteiro & 200 & 28 & 0 & 0 \\
\hline 24/ Monteiro & 44 & 19 & 5 & 26,32 \\
\hline 25/ Monteiro & 25 & 13 & 7 & 53,85 \\
\hline 26/ Monteiro & 30 & 19 & 13 & 68,42 \\
\hline 27/ Monteiro & 95 & 30 & 27 & 90,00 \\
\hline 28/Paulista & 34 & 10 & 2 & 20,00 \\
\hline 29/Amparo & 100 & 45 & 4 & 8,89 \\
\hline 30/Campina Grande & 45 & 20 & 14 & 70,00 \\
\hline 31/Soledade & 43 & 20 & 5 & 25,00 \\
\hline 32/ Maturéia & 27 & 15 & 3 & 20,00 \\
\hline TOTAL & 2412 & 734 & 330 & 44,96 \\
\hline
\end{tabular}

Quadro 2. Resultados dos testes de ELISA, para detecção de anticorpos contra o Map em 392 amostras de ovinos em 16 propriedades de 10 municípios do semiárido Paraibano

\begin{tabular}{lcccc}
\hline \multicolumn{1}{c}{ Fazenda/município } & Total & Testados & Positivos & $\%$ \\
\hline 1/Patos & 15 & 13 & 12 & 92,31 \\
2/Patos & 84 & 23 & 12 & 52,17 \\
3/Paulista & 380 & 34 & 31 & 91,18 \\
4/Paulista & 100 & 25 & 5 & 20,00 \\
5/São Mamede & 86 & 20 & 14 & 70,00 \\
6/São José do Espinharas & 475 & 40 & 37 & 92,50 \\
7/São José do Espinharas & 130 & 27 & 1 & 03,70 \\
8/Boa Vista & 100 & 25 & 4 & 16,00 \\
9/Boa Vista & 130 & 25 & 13 & 52,00 \\
10/Boa Vista & 250 & 25 & 14 & 56,00 \\
11/Boa Vista & 34 & 20 & 7 & 35,00 \\
12/Boa Vista & 150 & 25 & 13 & 52,00 \\
13/Boa Vista & 30 & 20 & 17 & 85,00 \\
14/Boa Vista & 207 & 24 & 20 & 83,33 \\
15/ São José do Bonfim & 98 & 26 & 12 & 46,15 \\
16/ São José do Bonfim & 190 & 20 & 0 & 0 \\
TOTAL & 2459 & 392 & 212 & 54,08
\end{tabular}

com frequência de $48,56 \%$, com os das raças puras, com frequência de $57,24 \%$, verificaram-se diferenças significativas $(\mathrm{P}=0,0270)$.

Em ovinos, a raça Santa Inês, em relação ao total de amostras, apresentou os maiores índices de animais soropositivos com 44,03\% (Quadro 5), porém não houve diferença estatística entre as raças estudadas $(P=0,5830)$.

Não foram verificadas diferenças significativas na frequência entre animais de diferentes idades (Quadro 6). Quanto
Quadro 3. Resultados dos testes de ELISA, para detecção de anticorpos contra o MAP em 14 municípios do semiárido Paraibano

\begin{tabular}{lcccccc}
\hline \multicolumn{1}{c}{ Munícipios } & \multicolumn{3}{c}{ Caprinos } & & \multicolumn{2}{c}{ Ovinos } \\
\cline { 2 - 3 } \cline { 5 - 6 } & No & Positivos № (\%) & & № & Positivos № (\%) \\
\hline Patos & 38 & $19(25,33)$ & & 36 & $24(66,66)$ \\
Paulista & 10 & $2(20,00)$ & & 59 & $36(61,01)$ \\
São José do Bonfim & - & - & & 46 & $12(26,08)$ \\
Maturéia & 15 & $3(20,00)$ & & - & - \\
Amparo & 169 & $65(38,46)$ & & - & - \\
Sumé & 108 & $41(37,96)$ & & - & - \\
Monteiro & 109 & $52(47,70)$ & & - & - \\
Prata & 137 & $69(50,36)$ & & - & - \\
Ouro Velho & 108 & $60(55,55)$ & & - & - \\
São José das Espinharas & - & - & & 67 & $38(56.71)$ \\
Boa Vista & - & - & & 164 & $88(53,65)$ \\
Campina Grande & 20 & $14(70,00)$ & & - & - \\
São Mamede & - & - & & 20 & $14(70,00)$ \\
Soledade & 20 & $5(25,00)$ & & - & - \\
TOTAL & 734 & $330(44,96)$ & & 392 & $212(54,08)$
\end{tabular}

Quadro 4. Resultados dos testes de ELISA, para detecção contra o Map em 734 amostras de caprinos de diferentes raças no semiárido Paraibano

\begin{tabular}{lccc}
\hline Raça & Total & Positivo & $\%$ \\
\hline Sem raça definida & 114 & 59 & 51,75 \\
Mestiça - Alpina Americana & 6 & 2 & 33,33 \\
Mestiça - Anglo-Nubiana & 25 & 14 & 56,00 \\
Mestiça - Boer & 1 & 0 & 0,00 \\
Mestiça - Parda & 91 & 36 & 39,56 \\
Mestiça - Saanen & 21 & 15 & 71,43 \\
Mestiça - Toggenburg & 20 & 9 & 45,00 \\
Anglo - Nubiana & 9 & 5 & 55,56 \\
Boer & 5 & 3 & 60,00 \\
Moxotó & 24 & 10 & 41,67 \\
Murciana & 3 & 2 & 66,67 \\
Alpina Britânica & 180 & 90 & 50,00 \\
Saanen & 204 & 131 & 64,22 \\
Savana & 22 & 14 & 63,64 \\
Toggenburg & 9 & 6 & 66,67 \\
TOTAL & 734 & 396 & 53,95
\end{tabular}

Quadro 5. Resultados dos testes de ELISA, para detecção de anticorpos contra o Map em 392 amostras de ovinos de diferentes raças no semiárido Paraibano

\begin{tabular}{lccc}
\hline \multicolumn{1}{c}{ Raças } & Total & Positivo & $\%$ \\
\hline Santa Inês & 352 & 155 & 44,03 \\
Dorper & 37 & 14 & 37,84 \\
Mestiça Santa Inês & 3 & 1 & 33,33 \\
TOTAL & 392 & 170 & 43,37
\end{tabular}

Quadro 6. Resultados dos testes de ELISA, para detecção de anticorpos contra o Map em caprinos e ovinos de diferentes idades no semiárido Paraibano

\begin{tabular}{cccccc}
\hline Idade & \multicolumn{2}{c}{ Caprinos } & & \multicolumn{2}{c}{ Ovinos } \\
\cline { 2 - 3 } \cline { 5 - 6 } & № & Positivos № $(\%)$ & & № & Positivos № (\%) \\
\hline 1 ano & 91 & $38(41,76)$ & & 71 & $25(35,21)$ \\
2 anos & 205 & $91(44,39)$ & & 99 & $60(60,67)$ \\
3 anos & 154 & $154(50,65$ & & 96 & $60(62,5)$ \\
4 anos & 269 & $113(42,00)$ & & 126 & $66(52,38)$ \\
5 anos & 12 & $8(66,67)$ & & 0 & 0 \\
6 anos & 3 & $2(66,67)$ & & 0 & 0 \\
TOTAL & 734 & 44,96 & & 392 & 53,83
\end{tabular}

ao escore corporal dos animais avaliados (Quadro 7) também não foram encontradas diferença significativa de frequência entre animais com diferentes escores. No entanto, 
Quadro 7. Resultados dos testes de ELISA, para detecção de anticorpos contra o Map em caprinos e ovinos com diferentes escores corporais no semiárido Paraibano

\begin{tabular}{lcclcc}
\hline \multicolumn{1}{c}{$\begin{array}{c}\text { Escore } \\
\text { corporal }\end{array}$} & \multicolumn{2}{c}{ Caprinos } & & \multicolumn{2}{c}{ Ovinos } \\
\cline { 2 - 3 } \cline { 5 - 6 } \cline { 5 - 6 } & No & Positivos № (\%) & & № & Positivos № (\%) \\
\hline 1 & 0 & 0 & & 7 & $7(100)$ \\
1,5 & 2 & $1(50)$ & & 13 & $10(76,92)$ \\
2 & 39 & $16(41,03)$ & & 39 & $30(76,92)$ \\
2,5 & 153 & $61(39,87)$ & & 110 & $63(57,27)$ \\
3 & 305 & $152(49,84)$ & & 129 & $64(49,61)$ \\
3,5 & 67 & $36(53,73)$ & & 36 & $14(38,89)$ \\
4 & 138 & $51(36,96)$ & & 45 & $22(48,89)$ \\
4,5 & 1 & 0 & & 4 & $1(25)$ \\
5 & 29 & $13(44,83)$ & & 9 & $1(11,11)$ \\
TOTAL & 734 & $330(44,96$ & & 392 & $212(54,08)$
\end{tabular}

em ovinos quando agrupados os animais com escore de 1 a 3 , a frequência $(59,39 \%-174 / 298)$ foi significativamente maior $(\mathrm{P}=0,034)$ que a frequência em ovinos com escore superior a $3(42,42 \%-38 / 94)$.

No exame microbiológico, colônias semelhantes às do Map foram observadas em 9 (6,58\%) das 180 amostras de fezes, sendo uma de caprinos e 8 de ovinos. Na coloração de Ziehl Nieelsen as bactérias apresentaram características morfo-tintorias de Map.

\section{DISCUSSÃO}

A alta frequência de anticorpos contra Map em caprinos e ovinos no semiárido da Paraíba alertam para a importância da doença na região. Essa frequência é maior que as observadas em outros países, sendo 11,7\% em ovinos na Espanha (Mainar-Jaime et al. 1998), 4,6\% a 15,3\% em caprinos na Coréia (Kyung et al. 2006), 11,6\% em ovinos e 4,6\% em caprinos na Índia (Tripathi et al. 2007) e de 8,5\% em ovinos jovens na Índia (Singh et al. 2007). As causas desta alta frequência devem ser investigadas; no entanto, é provável que seja devido ao tipo de manejo utilizado na região, onde apesar de muitos produtores utilizarem o manejo extensivo com animais a pastoreio na caatinga e baixa lotação, de 1 a 2 ovinos ou caprinos por hectare, os rebanhos são encerrados à noite, permanecendo misturados animais adultos com jovens e, frequentemente, em condições de higiene inadequadas. 0 estudo dos fatores de risco associados à ocorrência de anticorpos ajuda a esclarecer aspectos importantes da epidemiologia da doença na região.

A alta frequência de anticorpos sugere que a doença é importante na região e que causa prejuízos econômicos consideráveis; no entanto, é necessário quantificar essas perdas, determinando a ocorrência de doença clínica e subclínica. Para isso devem ser investigadas as causas de emagrecimento nos rebanhos caprino e ovino, estabelecendo o diagnóstico diferencial com outras causas de emagrecimento, incluindo as parasitoses e a subnutrição. A possibilidade de a doença estar ocasionando emagrecimento de animais é sugerida pela maior frequência de anticorpos em ovinos com escore corporal de 1 a 3 , quando comparada à dos ovinos com escore corporal acima de 3 . No entanto, em caprinos não foram observadas diferenças entre animais com diferente escore corporal.

Também devem ser pesquisados os possíveis fatores de riscos de transmissão da doença ao homem. Apesar de não comprovado é possível que o Map seja o agente da doença de Chron em humanos (Slana et al. 2009). Neste caso, a transmissão pode ocorrer através do leite, já que o Map resiste à pasteurização (Millar et al. 1996). A presença de Map no leite caprino comercializada no nordeste deve ser pesquisada, assim como possíveis medidas para evitar a transmissão deste agente ao homem.

Considerando a alta frequência de anticorpos para paratuberculose nos rebanhos ovino e caprino da Paraíba é difícil estabelecer medidas de controle, exceto recomendações de aspecto geral, úteis também, para o controle de outras doenças: higiene das instalações, separação dos animais por idade, e, na caprinocultura leiteira, separação dos cabritos com administração de colostro com tratamento térmico para CAE ou colostro de bovino. Recomenda-se, também, a eliminação de animais que permanecem magros, mesmo com boa alimentação. Neste ponto é necessário ressaltar que a prova de ELISA, recomendada para estimar a prevalência da doença nos rebanhos (Collins \& Sockett 1993), não é adequada para o diagnóstico, identificação e possível eliminação de animais afetados (Rossiter \& Burhans 1996). No Brasil, também em bovinos, espécie na qual a prevalência de casos clínicos é baixa, a frequência de anticorpos é alta, entre 30\% a 60,24\% (Rivera 1996, Laranja-da-Fonseca et al.1999).

No estudo microbiológico obteve-se uma baixo percentual de isolamento do Map, em 8 de 94 amostras de ovinos e em 1 de 86 amostras em caprinos. Esses resultados são semelhantes aos obtidos por outros autores (Coelho et al. 2007, Dimareli-Malli et al. 2009), confirmando a baixa sensibilidade do isolamento para o diagnóstico individual de paratuberculose.

\section{CONCLUSÃO}

Conclui-se que há uma alta frequência de anticorpos para Mycobacterium avium subsp. paratuberculosis em rebanhos de caprinos e ovinos no Estado da Paraíba, sendo necessário desenvolver novas pesquisas para determinar a importância econômica da doença clínica, como causa de emagrecimento, ou subclínica, como causa de menores índices de produção. No caso de confirmar a importância econômica da enfermidade deverão ser estudadas, também, medidas de controle adequadas para a região.

Agradecimentos.- Aos Agentes de Desenvolvimento Regional e Sustentável do (Projeto Bioma Caatinga) o qual tem como parceiros o SEBRAE, Fundação Banco do Brasil, cooperativas e associações, pela colaboração na execução das coletas, e ao CNPq pela concessão da bolsa do Mestrado e financiamento do projeto (Proc.471783/2008-0).

\section{REFERÊNCIAS}

Barker I.K. 2007. The alimentary system, p.1-296. In: Maxie M.G., Jubb Kennedy \& Palmer (Eds), Pathology of Domestic Animals. Vol.2. $5^{\text {th }}$ ed. Elsevier, Oxford.

Clarke C.J. \& Little D. 1996. The pathology of ovine paratuberculosis: Gross and histological changes in the intestine and other tissues. J. Comp. Pathol. 114(4):419-437.

Clarke C.J. 1997.The pathology and pathogenesis of paratuberculosis in ruminants and other species: A review. J. Comp. Pathol. 116(3):217261. 
Coelho A.C.M.L., Pinto S., Silva A.M., Coelho J. \& Rodrigues R.A. 2007. Seroprevalence of ovine paratuberculosis infection in the Northeast of Portugal. Small Rumin. Res. 71:298-303.

Collins M.T \& Socket D.C. 1993. Accuracy and economics of the USDA licensed enzyme- linked immunosorbent assay for bovine Paratuberculosis. J. Am. Vet. Med. Assoc. 203(10):1456-1463.

Dimareli-Malli Z., Stevenson K., Sarris K. \& Sossidou K. 2009. Study of microbiological and molecular typing aspects of paratuberculosis in sheep and goats in Northern Greece. Transbound. Emerg. Dis. 56(6/7):285-290.

Driemeier D., Cruz C.E.F., Gomes M.J.P., Cordellini G.L., Loretti A.P \& Colodel E.M. 1999. Aspectos clínicos e patológicos da paratuberculose em bovinos no Rio Grande do Sul. Pesq. Vet. Bras. 19(3/4):109-115.

Gomes M.J.P. 2002. Paratuberculose bovina: um grande desafio sanitário brasileiro. Minas de Leite 3:19-21.

GraphPad Instat versão 3.00 para Windows 95. GraphPad Software, San Diego, Califórnia, <www.graphpad.com>

Harris N.B. \& Barletta R.G. 2001. Mycobacterium avium subsp. paratuberculosis. Vet. Med. Clin. Microbiol. 14(3):489-512.

Kyung W.L., Byeong Y.J., Oung K.M., Dong K.Y., Su H.L., Ji Y.K \& Chang H.K. 2006. Seroprevalence of Mycobacteriumavium subspecies paratuberculosis in Korean Black Goats (Capra hircus aegragus). J. Vet. Med. Sci. 68(12):1379-1381.

Laranja F.L., Santos M.V., Pereira C.C., Olival A.A., Heinemann M.B. \& Richtzenhain L.J. 1999. Indentificação da presença de anticorpos contra Mycobacterium paratuberculosis em bovinos leiteiros do estado de São Paulo. $3^{\circ}$ Congresso Brasileiro de Buiatria, São Paulo. Arqs Inst. Biológico, São Paulo, 66(Supl.):122.

Mainar-Jaime R.C. \& Vazquez-Boland J.A. 1998. Factors associated with seroprevalence to Mycobacterium paratuberculosis in small ruminant farms in the Madrid region (Spain). Prev. Vet. Med. 34:317-327.

Millar D., Ford J., Sanderson J., Withey S., Tizard M., Daron T. \& Herman-Taylor J. 1996. IS900 PCR to detect Mycobacterium paratuberculosis in retail supplies of whole pasteurized cows' milk in England and Wales. Appl. Environ. Microbiol. 62:3446-3452.

Moravkova M., Hlozek P., Beran V., Pavlik I., Preziuso S., Cuteri V. \& Bartos M. 2008. Strategy for the detection and differentiation of Mycobacterium avium species in isolates and heavily infected tissues. Res. Vet. Sci. 85(2):257-264.

Mota R.A., Pinheiro Junior J.W., Gomes M.J.P., Peixoto R.M., Maia F.C.L., Brito M.F., Chies J.A.B., Snel G.G.M., Bercht B.S. \& Juffo G.D. 2007. Paratuberculose em um rebanho bovino leiteiro no estado de Pernambuco, PE. Arqs Inst. Biol., São Paulo, 74(2):73-79.

Oliveira D.M., Pimentel L.A., Rodrigues T.A., Dantas A.F.M., Neto E.G.M., Simões S.V.D. \& Riet-Correa F. 2008. Paratuberculose em bovinos no estado da Paraíba. Encontro Nacional de Diagnóstico Veterinário (Endivet), Campo Grande, MS, p.203-204. (Resumo)

Oliveira D.M., Riet-Correa F., Galiza G.J.N., Assis A.C.O., Dantas A.F.M., Ban- darra P.M. \& Garino Jr. F.2010. Paratuberculose em caprinos e ovinos no Brasil. Pesq. Vet. Bras 30(1):67-72.

Ott S.L., Wells S.J. \& Wagner B.A. 1999. Herd-level economic losses associated with Johne's disease on US dairy operations. Prev. Vet. Med. 40(3/4):179-192.

Poester F.P. \& Ramos E.T. 1994. Infecção experimental em caprinos com Mycobaterium paratuberculosis de origem bovina. Ciência Rural 24(2):333-337.

Portugal M.A.S.C., Pimentel, J.N., Saliba, A.M., Baldassi L. \& Sandoval E.F.D. 1979. Ocorrência de paratuberculose no estado de Santa Catarina. Biológico, São Paulo, 45:19-24.

Radostits O.M., Gay C.C., Hinchcliff K.W. \& Constable P.T. 2007. Veterinary Medicine. $10^{\text {th }}$ ed. Saunders Elsevier, Edinburgh, p.1017-1044.

Ramos E.T., Poster F.P., Correia B.L., de Oliveira S.J., Rodrigues N.C. \& Canabarro C.E. 1986. Paratuberculose em bovinos no estado do Rio Grande do Sul. Hora Vet. 34:28-32.

Riet-Correa F. \& Driemeier D. 2007. Paratuberculose, p.407-414. In: Riet-Correa F., Schild A.L., Lemos R.A.A. \& Borges J.R.J. (Eds), Doenças de Ruminantes e Equinos. Vol.1. $3^{\mathfrak{a}}$ ed. Pallotti, Santa Maria, RS.

Rivera F.E.B. 1996. Levantamento sorológico utilizando-se a técnica de ELISA em rebanhos apresentando problemas reprodutivos. I. Enterite paratuberculose. Anais I Encontro de Laboratórios de Diagnóstico Veterinários do Cone do Sul, p.20-22.

Rossiter C.A. \& Burhans W.S. 1996. Farm-specific approach to paratuberculosis (John`s disease) control. Vet. Clin. North Am., Food Anim Pract. 12:383-415.

Singh S.V., Singh A.V., Singh P.K., Gupta V.K., Kumar S. \& Vohra J. 2007. Sero-prevalence of paratuberculosis in young kids using 'Bison type' Мyсоbacterium avium subsp. paratuberculosis antigen in plate ELISA. Small Rumin. Res. 70(2/3):89-92.

Stabel J.R. 1997. An improved method for cultivation of Mycobacterium paratuberculosis from bovine fecal samples and comparison to three methods. J. Vet. Diagn. Invest. 3:368-373.

Stabel J.R. 1998. Johne's disease a hidden treat. J. Dairy Sci. 81:283-288.

Slana I., Liapi M., Moravkova M., Kralova A. \& Pavlik I. 2009. Mycobacterium avium subsp. paratuberculosis in cow bulk tank milk in Cyprus detected by culture and quantitative IS 900 and F57 real-time PCR. Prev. Vet. Med. 89(3/4):223-226.

Tripathi B.N., Sivakumar P., Paliwal O.P. \& Singh N. 2006. Comparison of tissue PCR, bacterial culture, johnin and serological test in the diagnosis of naturally occurring paratuberculosis in goats. Vet. Microbiol. 116:129137.

Tripathi B.N., Sonawane G.G., Munjal S.K., Bind R.B., Gradinaru D., Dubey S.C., Mondal D., Paliwal O.P. \& Singh N. 2007. Seroprevalence of paratuberculosis in selected population of ruminants in India. Proc. $9^{\text {th }}$ International Colloquium on Paratuberculosis, Tsukuba, Japan, p.246-249. 